Published in final edited form as:

Lancet Diabetes Endocrinol. 2019 March 01; 7(3): 231-240. doi:10.1016/S2213-8587(19)30026-9.

\title{
The Obesity Transition: Stages of the global epidemic
}

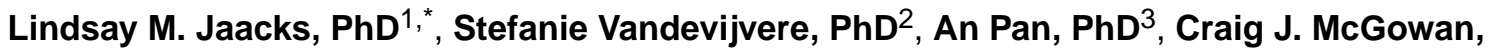 \\ MS $^{1}$, Chelsea Wallace, $\mathbf{M S}^{2}$, Fumiaki Imamura, $\mathrm{PhD}^{4}$, Dariush Mozaffarian, MD ${ }^{5}$, Boyd \\ Swinburn, MD ${ }^{2,6}$, Majid Ezzati, FMedSci ${ }^{7}$
}

1Department of Global Health and Population, Harvard T.H. Chan School of Public Health, Boston, MA, USA ${ }^{2}$ School of Population Health, The University of Auckland, Auckland, New Zealand ${ }^{3}$ Department of Epidemiology and Biostatistics, Ministry of Education and State Key Laboratory of Environmental Health (Incubating), School of Public Health, Tongji Medical College, Huazhong University of Science and Technology, Wuhan, Hubei, China ${ }^{4}$ MRC Epidemiology Unit, University of Cambridge School of Clinical Medicine, Cambridge, UK ${ }^{5}$ Friedman School of Nutrition Science and Policy, Tufts University, Boston, MA, USA ${ }^{6}$ Global Obesity Centre, Deakin University, Melbourne, Australia ${ }^{7}$ School of Public Health, Imperial College London, London, UK. MRC-PHE Centre for Environment and Health, Imperial College London, London, UK. WHO Collaborating Centre on NCD Surveillance and Epidemiology, Imperial College London, London, UK

\section{Abstract}

Our aim was to consolidate the evidence on the epidemiology of obesity into a conceptual model of the 'obesity transition'. Illustrative examples from the thirty most populous countries, representing $77.5 \%$ of the world's population, were used. Stage 1 of the obesity transition is characterised by a higher prevalence in women compared to men, in those with higher compared to lower socioeconomic status, and adults compared to children. Many countries in South Asia and sub-Saharan Africa are at this stage. In Stage 2, there is a large increase in the prevalence among adults, a smaller increase among children, and a narrowing of the gender gap and socioeconomic differences among women. Many Latin American and Middle Eastern countries are at this stage. High-income East Asian countries are also at this stage, albeit with a much lower prevalence of obesity. Stage 3 occurs when the prevalence of obesity among those with lower socioeconomic status surpasses that among those with higher socioeconomic status and plateaus in obesity may be observed among women with high socioeconomic status and children. Most European countries are currently at this stage. There are too few signs of countries entering into the proposed final stage of declining obesity prevalence to determine demographic patterns. This conceptual model is intended to provide guidance to researchers and policymakers in identifying the current stage of

*Corresponding author: Lindsay M. Jaacks, PhD, Department of Global Health and Population, Harvard T.H. Chan School of Public Health, 655 Huntington Avenue, Boston, MA 02115, USA, jaacks@ @sph.harvard.edu, Tel.: +1 617-432-2505.

Contributors: LMJ, SV, AP, BS, and ME co-conceived the study. LMJ conducted the literature review. LMJ wrote the first draft of the manuscript with significant inputs from BS and ME. All authors provided critical inputs and approved the final version. LMJ is the guarantor of the work.

Declaration of interests: ME reports a charitable grant from AstraZeneca Young Health Programme, and personal fees from Prudential, Scor, and Third Bridge, all outside the submitted work. 
the obesity transition in a population, anticipate sub-populations that will experience obesity in the future, and enact proactive measures to attenuate the transition, taking into consideration local contextual factors.

\section{Introduction}

The concept of 'transitions' has been applied in demography, ${ }^{1}$ epidemiology, ${ }^{2}$ nutrition, ${ }^{3}$ tobacco, ${ }^{4}$ and cancer, ${ }^{5}$ among other fields, ${ }^{6}$ to describe trends in important population health parameters in order to provide insights into underlying determinants, positive deviants, and future trends. One of today's most important population health parameters is high body mass index (BMI): of the 84 risk factors evaluated by the Global Burden of Disease Study in 2017, high BMI had, by far, the greatest relative increase in exposure since 1990 and was among the top five risk factors in terms of attributable deaths and disability-adjusted lifeyears. ${ }^{7}$ There has been very little implementation of comprehensive, policy-based approaches, ${ }^{8}$ and, as a result, no country or sub-population within a country has witnessed a decline in obesity. This represents one of the biggest population health failures of our time.

Several prior global analyses of mean population BMI and/or prevalence of overweight and obesity exist, ${ }^{9-14}$ but none has explored the stages of the obesity transition as it spreads across sub-populations within countries. Although there is massive variability across countries in the prevalence of obesity as defined by a BMI $30 \mathrm{~kg} / \mathrm{m}^{2}$, for example, ranging from $0.2 \%$ in Vietnamese women to $65.3 \%$ in American Samoan women, ${ }^{9}$ we propose that there are discernible patterns in broad changes in obesity prevalence over time and that these can be grouped as a relatively predictable set of stages of the 'obesity transition'. Understanding these patterns will help to guide future research, improve predictions about future trends, and provide important context for policy and community-based approaches to obesity prevention. Furthermore, doing so may help to explain some of the wide disparities in obesity between and within countries, ${ }^{15}$ which flow into disparities in morbidity and mortality. ${ }^{16,17}$

The aim of this paper was to consolidate the evidence on the epidemiology of obesity into a proposed conceptual model of the obesity transition. Illustrative examples from the thirty most populous countries in the world (herein referred to as 'mega countries'), which represent $77.5 \%$ of the world's population across various stages of economic development, were used and regional exceptions were described. Future trends in these countries will undoubtedly have a major impact on progress to achieve the WHO target of halting the rise in obesity by 2025 .

\section{Search Strategy and Selection Criteria}

The availability of longitudinal weight and height data from countries throughout the world has made it possible to define the broad stages of the obesity transition and predict which sub-populations will be at greatest risk of obesity as a country develops economically. These are patterns of transition and the "cut-offs" to define each stage of the transition in terms of absolute obesity prevalence are only descriptive. The present investigation incorporated standard demographic parameters routinely collected by governments, e.g., sex, age 
(children versus adults), residence (geographic subdivisions such as states or provinces), and socioeconomic status (educational attainment and household wealth), to define key subpopulations and facilitate dissemination of the model to stakeholders, support new rapid assessments or secondary data analyses, and allow for subsequent refinement of the model.

We rely on publicly available data from the NCD Risk Factor Collaboration (NCD-RisC) on the age-standardised prevalence of obesity among adults ( $\geq 20$ years) and children (5-19 years), stratified by sex. Differences in the prevalence of obesity according to socioeconomic status were obtained from recent and/or commonly referenced global analyses. ${ }^{18-24}$ We also searched the reference lists of these articles and selected those we judged relevant. Because these previous analyses largely utilised Demographic and Health Survey (DHS) data, and thus were restricted to women of reproductive age in low- and middle-income countries, or World Health Survey data, and thus were restricted to 2002-2003, we also conducted a review of articles published in PubMed in the past 10 years identified using the search terms "obesity" AND "[country name]" for the 30 mega countries.

\section{Stages of the Obesity Transition}

In 1975 , the majority $(16 / 30 ; 53 \%)$ of mega countries had an obesity prevalence less than 5\% across all demographic sub-populations (Supplemental Online Material, pp. 2-3). However, several countries had already entered into what we propose as Stage 1 of the obesity transition (Figure 1), which is characterised by a rise in obesity prevalence to above $5 \%$ in women - but not higher than $20 \%$, which was the highest prevalence among the 30 mega countries in 1975 - and a distinctly higher prevalence in women compared to men and in adults compared to children. In 1975, countries at Stage 1 were Mexico, Colombia, and Brazil in Latin America, several Middle Eastern countries (Egypt, Turkey, and Iran), Russia, and South Africa, where the prevalence was 2-9 times higher among women compared to men, and the prevalence among children was less than 5\%.

Forty years later, in 2016, only Viet Nam, where the prevalence of obesity was less than 5\% across all demographic sub-populations, had not entered the obesity transition. All other lower income mega countries (per capita gross national income [GNI] less than 10,000 current international dollars) had entered Stage 1, including Bangladesh, India, Pakistan, and Myanmar in South Asia; and DR Congo, Ethiopia, Kenya, Nigeria, and Tanzania in subSaharan Africa (Figure 2). In these countries, the prevalence of obesity among women was $5-14 \%$ and notably higher among women (average of about 10\%) compared to men (average of about $4 \%$ ), and in adults (average of about $7 \%$ ) compared to children (average of about 2\%) (Supplemental Online Material, pp. 2-3). Also in Stage 1, though further along within the stage, were countries with a higher per capita GNI in the region of Southeast Asia: the Philippines, Indonesia, and Thailand (Figure 2).

Stage 1 is further characterised by a higher prevalence of obesity among those with higher socioeconomic status compared to those with lower socioeconomic status, and this is especially pronounced among women. An analysis of DHS data spanning 1991 to 2009 from 56 countries including the Stage 1 countries of Bangladesh, India, DR Congo, Ethiopia, Kenya, Nigeria, Tanzania, and the Philippines, found that the least educated women had an 
11 percentage points lower overweight or obesity (BMI $\geq 25 \mathrm{~kg} / \mathrm{m}^{2}$ ) prevalence compared to the most educated women. ${ }^{20}$ Whilst prevalence data for obesity among men and children in these settings disaggregated by socioeconomic status are rare, similar observations of positive associations of household wealth and educational attainment with overweight and obesity have been reported among adult men in Bangladesh and Indonesia. ${ }^{25-27}$

Stage 2 of the obesity transition is broadly characterised by a large increase in the prevalence among adults, a smaller increase among children, and a narrowing of the gender gap and socioeconomic differences among women (Figure 1). The prevalence of obesity among women at this stage tends to be in the range of $25-40 \%$; that among men near to $20 \%$; and that among children near to 10\%. All aforementioned countries at Stage 1 in 1975 (e.g., Mexico, Colombia, Brazil, Egypt, Turkey, Iran, Russia, and South Africa) were at Stage 2 by 2016 (Figure 3). The exceptional Stage 2 countries include higher income East Asian mega countries (e.g., China, South Korea, and Japan), where the prevalence of obesity defined using the traditional criterion (BMI $230 \mathrm{~kg} / \mathrm{m}^{2}$ ) was in the range of 4-7\% among women; about 5\% among men; and in the range of 2-15\% among children (Figure 4).

With regards to the narrowing of the gender and, among women, socioeconomic differences in Stage 2, several previous country-specific analyses provide some insight, though cover relatively short periods of time and as such should be interpreted with some caution. Nationally representative data from South Africa, for example, indicated that men experienced much greater relative increases in the prevalence of obesity from 2008 to 2012 than women, ${ }^{28,29}$ and that the positive association between socioeconomic status and obesity weakened among women though it remained positive among men. ${ }^{29,30}$ Colombia provides another illustrative example of the narrowing of the socioeconomic difference: the greatest relative increases in obesity in more recent years (2005-2010) were among lowincome individuals compared to high-income individuals, and, similar to South Africa, the positive association between wealth and obesity was stronger among men than women. ${ }^{31}$ In Egypt, analysis of DHS data from 1992-1995 to 2005-2008 also found that the greatest relative increases in the prevalence of obesity were among women with no/primary education and in the poorest wealth quintile. ${ }^{32}$

Several middle-income countries are even further along in Stage 2 in terms of closing gender and socioeconomic differences, including Brazil, Turkey, Russia, South Korea, and China. In Brazil, whilst the prevalence of obesity decreased among high-income women from 1989 to $1998,{ }^{33}$ it continued to increase among low-income women and across all income groups in men. ${ }^{28}$ Notably, this example is the only instance we identified globally of a documented decline in obesity prevalence among a major sub-population within a country, raising concern it may be unique or related to chance or sampling error. Cross-sectionally in Turkey, regions that are more economically developed, where the education level is higher, had a lower obesity prevalence among women compared to less developed regions, though similar patterns were not seen for men. ${ }^{34,35}$ Similarly in Russia, women with a higher education were less likely to have obesity, but the effect of education on obesity among men was nonsignificant. ${ }^{36}$ In South Korea and China, women with lower educational attainment are more likely to have obesity compared to women with higher educational attainment, though the opposite is true for men. ${ }^{37,38}$ 
Stage 3 of the obesity transition is primarily characterised by a closing of the gender gap, and a reversal of the socioeconomic differences due to an acceleration of obesity among previously lower-BMI sub-populations in Stage 2 (as opposed to declines in the prevalence of obesity in any sub-population). The prevalence among children continues to increase, although the patterns by gender and socioeconomic status are more mixed than for adults. In 2016, the USA and all analysed European countries (e.g. Italy, France, Spain, Germany, and the UK) were at Stage 3 (Figure 5).

Several previous country-specific analyses of obesity lend support to the socioeconomic reversal of risk at this stage. In Spain, lower-income regions in the south have a higher obesity prevalence compared to higher-income regions in the north, ${ }^{39}$ and low-income individuals in the UK are more likely to have obesity than their high-income counterparts. ${ }^{40}$ In an analysis of 15 European countries, from 1990 to 2010, the increase in obesity prevalence, based on self-reported height and weight, among men was greater in the low educational group compared to the high educational group in all countries except Ireland and Scotland. ${ }^{41}$ Among women, the increase was larger in the low educational group in all countries except Ireland, Finland, Hungary, Austria, and Italy. ${ }^{42}$

Globally, the upward trajectory of the obesity epidemic has been driven by strong period effects, perhaps with some cohort effects in more recent decades, suggesting that increasingly obesogenic influences have affected the whole population, ${ }^{43-46}$ albeit differently for different sub-populations as explained for Stages 1, 2, and 3. The putative final stage of the obesity transition would be a declining prevalence. Will Stage 4 of the obesity transition simply be the reverse of the patterns seen in earlier stages? Since most of the early evidence of the obesity epidemic flattening is for children, ${ }^{47}$ especially among those with high socioeconomic status in high-income countries, this may suggest a strong cohort effect seen in Stage 4. In other words, potential for reducing obesity prevalence in adults may be largely determined by leaner children entering adulthood, rather than reducing prevalence in the current generations of adults. This is important because it may contribute to an increase in health inequalities in Stage 4, as trend data on the prevalence of obesity among school-aged children from the UK suggest. ${ }^{48}$ Whilst these ideas about Stage 4 are largely speculative without more data, understanding the patterns of increasing obesity in Stages 1-3 helps to consider the likely scenarios for Stage 4.

\section{Modifiers of the Obesity Transition}

Across countries, considerable variation is seen in the prevalence of obesity and the slope of obesity trajectories over time. This suggests that the underlying global determinants of obesity ${ }^{49}$ have a varying distribution or intensity across geographies and time, and/or the global determinants influence risk of obesity differently depending on other local contextual factors. There are large, well-described environmental differences across countries, which are likely to be moderators of the effects of globalisation on obesity prevalence. Such environmental factors could be socio-cultural (e.g., cuisines, body size perceptions, and cultural characteristics), economic (e.g., national wealth and distribution of wealth), policy (e.g., political and regulatory regimes), or physical (e.g., built environment) ${ }^{50}$ Biological differences between populations (e.g., in genetics, epigenetics, or the microbiome) creating 
obesity susceptibilities is also a possibility. Heterogeneity at the extremes can give insight into these potential modifiers.

The main cluster of exceptional countries is in East Asia, where adults have very low absolute levels of obesity and less steep obesity trajectories compared to mega countries at similar stages of economic development (Figure 4). Here, the globalisation drivers, which are increasing obesity in all countries, have interacted with local contextual determinants to markedly attenuate the epidemic. East Asians carry their propensity for low BMI when they migrate to other countries ${ }^{51}$ suggesting that these determinants are, in large part cultural, rather than geographical. While it is unlikely that common genetic variants account for these exceptional populations, given that identified common genetic variants explain less than $3 \%$ of the heritability of obesity, ${ }^{52}$ other more distributed and rare variants, ${ }^{53}$ epigenetic differences, ${ }^{54}$ or microbiome differences ${ }^{55}$ could partly account for these observations.

Cultural factors could also play a role. East Asian countries such as Japan are broadly classified as collectivistic cultures in which conformity to social norms may be a stronger driver of food behaviours than in more individualistic countries such as the USA where emotional and environmental triggers are more powerful drivers ${ }^{56,57}$ and obesity is largely viewed as a matter of personal responsibility. ${ }^{58} \mathrm{~A}$ recent ecological analysis of 54 countries found that collectivism was significantly associated with lower obesity, even accounting for other cultural dimensions and per capita GNI. ${ }^{59}$ This confirmed findings from a previous study with fewer countries (only two from East Asia) that also reported an inverse association between collectivism and BMI. ${ }^{60}$ Further research is needed to understand the role that collectivistic culture and other cultural determinants could play in mitigating obesity. As an example of this, in Japan, cultural values such as the importance of quality, traditional, small-portion meals have been translated into practices such as the school food provision and nutrition curriculum, and education on nutrition and health, manners, aesthetics, and hygiene are incorporated into the school lunch. ${ }^{61}$ If implemented as part of a comprehensive approach, such policies, grounded in cultural values, could impact the trajectory of the obesity epidemic.

Notably, in countries where sub-national estimates of obesity prevalence can be calculated such as India, China, Nigeria, and the USA (Box 1), regions and states also vary considerably in their stages of the obesity transition. Such regional effects often track with socioeconomic factors and disparities, such as in education, income, and access to societal infrastructure. Understanding the effects of national and sub-national modifiers on absolute levels of obesity and trajectories will be an important area of future research and refinement of the obesity transition theory.

\section{Implications}

We propose three broad stages of the obesity transition that may help to predict which subpopulations will be at greatest risk of obesity as a country passes through each stage. Where countries fall in terms of their magnitudes and trajectories of obesity prevalence varies substantially, suggesting that local moderating factors may interact with the global drivers to attenuate or accentuate their impacts and/or that there are differences in intensity of exposure 
to the global drivers. There are too few signs of countries entering a proposed fourth stage of declining obesity prevalence to determine the potential demographic patterns, except that higher-income young children in some high-income countries may be the first group to show flattening in prevalence. ${ }^{48}$ This may worsen existing socioeconomic inequities in obesity in these countries. Currently, whilst the prevalence of obesity may no longer be rapidly increasing in some sub-populations at later stages of the transition, it is plateauing at high rates. This has very important adverse implications for future obesity-related disability and mortality.

Existing monitoring systems for obesity, such as the NCD Risk Factor Collaboration ${ }^{9,10}$ and WHO Global Health Observatory, ${ }^{62}$ the Global Burden of Disease Study, ${ }^{13}, 14$ and the Global Nutrition Report, ${ }^{63}$ are rich sources of quantitative data on age- and sex-specific BMI, overweight, and obesity over time. The obesity stages identified herein complement such quantitative data by providing a theoretical framework to describe the underlying findings and transitions. We leave to future research the task of evaluating possible factors that determine the underlying drivers of transition between stages. Governments seeking specific recommendations to combat the obesity epidemic-at any stage of the transition-can consult The Lancet Commission report, ${ }^{64}$ two previous Series on obesity published in The Lancet in 2011 49, 65-67 and 2015,8, 68-72 the 2017 Lancet Diabetes and Endocrinology Series on obesity, ${ }^{73-75}$ and several WHO guidelines, for example, the 'Global Action Plan on Physical Activity 2018-2030'76 and the 'Report of the Commission on Ending Childhood Obesity'. ${ }^{77}$

Several questions remain to be answered by further research, including: What determines how quickly a country transitions from Stage 1 to Stage 2, and from Stage 2 to Stage 3? Will countries transition into a final stage of declining obesity prevalence? If so, what is the lag time between Stage 3 and Stage 4? These future refinements may mirror the theory of the epidemiological transition, which, when first proposed by Omran in 1971 did not include a stage of declining degenerative disease ${ }^{2}$ and was refined to include this stage some 15 years later. $^{78}$

In addition, our new finding of substantial variation in obesity prevalence across states in India-and the lack of such estimates for most of the other mega countries evaluated-support the need for representative sub-national data on obesity to better inform programmes and policies, as well as generate new hypotheses regarding the underlying mechanisms leading to obesity. Finally, there are approximately 300 million Indigenous peoples living in 90 countries across the globe,${ }^{79}$ and data suggest that Indigenous peoples are at increased risk of developing obesity. ${ }^{80-83}$ To date, most data on obesity in Indigenous peoples are from just four countries: Australia, New Zealand, the USA, and Canada. ${ }^{79}$ This data gap must be addressed in order to integrate trends in this important sub-population into the larger obesity transition framework.

Other global transitions have been described. The health or demographic transition is a process whereby mortality rates decline, and, later on, fertility rates also decline. ${ }^{1}$ The epidemiological transition is a shift in cause of death from infection and undernutrition to chronic, noncommunicable diseases and injuries. ${ }^{2}$ The nutrition transition has been proposed 
as a set of dietary changes related to economic development away from traditional healthful diets and toward a pattern of Westernized, highly processed and refined foods. ${ }^{3}$ Some of the underlying determinants of these transitions, namely urbanisation, economic development, and cultural changes including increasing individualism and consumerism, may also underlie the obesity transition. Massive changes have also occurred in the global food system, including changes in breeding, agricultural production, and transport of starch-rich crops; in food manufacturing, processing, preservation, and marketing; and in frequency and timing of eating, drinking, and snacking episodes. Ultimately, a robust, quantitative understanding of these different drivers and their potential modifiers will facilitate successful strategies to push societies into the final proposed stage of the obesity transition, i.e., declining obesity prevalence. If such strategies are not vigorously evaluated, implemented, and scaled - and in the absence of strong public demand and political will for change, they are not likely to be - societies will witness continuing high rates of obesity with accompanying tremendous societal health and economic costs.

The proposed obesity transition theoretical framework is not without limitations. Firstly, we used BMI, which, while consistent with prior global analyses of obesity, ${ }^{9-14}$ is a surrogate measure of excess body fat. However, direct measures such as dual-energy X-ray absorptiometry (DEXA) are far too expensive and inconvenient to be used in the large, population-based studies required to monitor the obesity transition. Moreover, a systematic review of surrogate measures of excess body fat including BMI but also waist circumference and waist-to-hip ratio did not find that any of the measures had superior discriminatory capability of adverse cardio-metabolic outcomes. ${ }^{84} \mathrm{We}$ used a single cut-point to define obesity ( $230 \mathrm{~kg} / \mathrm{m}^{2}$ ), as supported by large cohort studies and cohort pooling studies in Asian and Western populations, which have shown that the risk of adverse cardiometabolic outcomes increases from similarly low BMIs in both groups. ${ }^{85-88}$ This is also consistent with WHO recommendations. ${ }^{89}$ Finally, the proposed framework also simplifies age by comparing children aged 5-19 years and adults aged $\geq 20$ years, which overlooks potential differences between younger children (eg, 5-9 years) versus adolescents (eg, 10-19 years) and reproductive-aged adults (eg, 20-49 years) versus older adults (eg, 265 years). More detailed appraisals of the obesity transition should consider these narrower age groups.

The obesity transition model proposed herein may provide guidance to researchers and policymakers, particularly to:

- $\quad$ Classify the obesity epidemic in a progressive, predictable sequence;

- Identify the current stage of the obesity transition in a population, and evaluate potential for specific preventive interventions that may be most suited to a particular stage;

- Anticipate sub-populations that will experience obesity in the future as economies develop, and enact proactive measures to attenuate the transition;

- Use as a reference for current and past staging along the transition, thus useful for monitoring and surveillance purposes and comparisons to other nations. 
- $\quad$ Encourage ongoing surveillance efforts to focus on addressing underserved populations.

The intent of the obesity transition model is to provide such a tool, and to encourage ongoing research, surveillance, and intervention efforts to address the global obesity epidemic.

\section{Supplementary Material}

Refer to Web version on PubMed Central for supplementary material.

\section{Acknowledgements}

We would like to thank Pascal Geldsetzer, $\mathrm{MBChB}, \mathrm{ScD}$, for his contribution to the analysis of obesity prevalence by state in India using the District-Level Household Survey-4 and the second update of the Annual Health Survey.

Funding

None.

\section{References}

1. Thompson WS. Population. American Journal of Sociology. 1929; 34:959-75.

2. Omran A. The epidemiologic transition: a theory of the epidemiology of population change. The Milbank Memorial Fund Quarterly. 1971; 49(4):509-38. [PubMed: 5155251]

3. Popkin BM. Nutritional patterns and transitions. Population and Development Review. 1993; 19(1):138-57.

4. Lopez AD, Collishaw NE, Piha T. A descriptive model of the cigarette epidemic in developed countries. Tob Control. 1994; 3(3):242.

5. Bray F, Jemal A, Grey N, Ferlay J, Forman D. Global cancer transitions according to the Human Development Index (2008-2030): a population-based study. Lancet Oncology. 2012; 13(8):790 801. [PubMed: 22658655]

6. Smith KR, Ezzati M. How environmental health risks change with development: the epidemiologic and environmental risk transitions revisited. Annu Rev Environ Resour. 2005; 30:291-333.

7. Stanaway JD, Afshin A, Gakidou E, et al. Global, regional, and national comparative risk assessment of 84 behavioural, environmental and occupational, and metabolic risks or clusters of risks for 195 countries and territories, 1990, 2013, 2017: a systematic analysis for the Global Burden of Disease Study 2017. Lancet. 2018; 392(10159):1923-94. [PubMed: 30496105]

8. Roberto CA, Swinburn B, Hawkes C, et al. Patchy progress on obesity prevention: emerging examples, entrenched barriers, and new thinking. Lancet. 2015; 385(9985):2400-9. [PubMed: 25703111]

9. NCD Risk Factor Collaboration (NCD-RisC). Worldwide trends in body-mass index, underweight, overweight, and obesity from 1975 to 2016: a pooled analysis of 2416 population-based measurement studies in 128. 9 million children, adolescents, and adults. Lancet. 2017; 390(10113):2627-42. [PubMed: 29029897]

10. NCD Risk Factor Collaboration (NCD-RisC). Trends in adult body-mass index in 200 countries from 1975 to 2014: a pooled analysis of 1698 population-based measurement studies with $19 \cdot 2$ million participants. Lancet. 2016; 387(10026):1377-96. [PubMed: 27115820]

11. Finucane MM, Stevens GA, Cowan MJ, et al. National, regional, and global trends in body-mass index since 1980: systematic analysis of health examination surveys and epidemiological studies with 960 country-years and 9.1 million participants. Lancet. 2011; 377(9765):557-67. [PubMed: 21295846]

12. Stevens GA. National, regional, and global trends in adult overweight and obesity prevalences. Population Health Metrics. 2012; 10(1):22. [PubMed: 23167948] 
13. Afshin A, Forouzanfar MH, Reitsma MB, et al. Health effects of overweight and obesity in 195 countries over 25 years. N Engl J Med. 2017; 377(1):13-27. [PubMed: 28604169]

14. Ng M, Fleming T, Robinson M, et al. Global, regional, and national prevalence of overweight and obesity in children and adults during 1980-2013: a systematic analysis for the Global Burden of Disease Study 2013. Lancet. 2014; 384(9945):766-81. [PubMed: 24880830]

15. GBD 2016 Risk Factors Collaborators. Global, regional, and national comparative risk assessment of 84 behavioural, environmental and occupational, and metabolic risks or clusters of risks, 1990-2016: a systematic analysis for the Global Burden of Disease Study 2016. Lancet. 2017; 390:1345-422. [PubMed: 28919119]

16. Kontis V, Bennett JE, Mathers CD, Li G, Foreman K, Ezzati M. Future life expectancy in 35 industrialised countries: projections with a Bayesian model ensemble. Lancet. 2017; 389(10076):1323-35. [PubMed: 28236464]

17. Hoffmann R, Eikemo TA, Kulhanova I, et al. Obesity and the potential reduction of social inequalities in mortality: evidence from 21 European populations. Eur J Public Health. 2015; 25(5):849-56. [PubMed: 26009611]

18. Kim R, Kawachi I, Coull BA, Subramanian SV. Contribution of socioeconomic factors to the variation in body-mass index in 58 low-income and middle-income countries: an econometric analysis of multilevel data. Lancet Global Health. 2018; 6(7):e777-e86. [PubMed: 29903378]

19. Pampel FC, Denney JT, Krueger PM. Obesity, SES, and economic development: a test of the reversal hypothesis. Soc Sci Med. 2012; 74(7):1073-81. [PubMed: 22341204]

20. Goryakin Y, Suhrcke M. Economic development, urbanization, technological change and overweight: What do we learn from 244 Demographic and Health Surveys? Econ Hum Biol. 2014; 14:109-27. [PubMed: 24457038]

21. Jones-Smith JC, Gordon-Larsen P, Siddiqi A, Popkin BM. Cross-national comparisons of time trends in overweight inequality by socioeconomic status among women using repeated crosssectional surveys from 37 developing countries, 1989-2007. Am J Epidemiol. 2011; 173(6):66775. [PubMed: 21300855]

22. Kinge JM, Strand BH, Vollset SE, Skirbekk V. Educational inequalities in obesity and gross domestic product: evidence from 70 countries. J Epidemiol Community Health. 2015; 69(12):1141-6. [PubMed: 26179449]

23. Masood M, Reidpath DD. Effect of national wealth on BMI: An analysis of 206,266 individuals in 70 low-, middle-and high-income countries. PLoS One. 2017; 12(6):e0178928. [PubMed: 28662041]

24. Kim R, Kawachi I, Coull BA, Subramanian SV. Patterning of individual heterogeneity in body mass index: evidence from 57 low-and middle-income countries. Eur J Epidemiol. 2018:1-10.

25. Biswas T, Garnett SP, Pervin S, Rawal LB. The prevalence of underweight, overweight and obesity in Bangladeshi adults: Data from a national survey. PLoS One. 2017; 12(5):e0177395. [PubMed: 28510585]

26. Bulbul T, Hoque M. Prevalence of childhood obesity and overweight in Bangladesh: findings from a countrywide epidemiological study. BMC Pediatr. 2014; 14(1):86. [PubMed: 24690395]

27. Christiani Y, Byles JE, Tavener M, Dugdale P. Gender Inequalities in Noncommunicable Disease Risk Factors Among Indonesian Urban Population. Asia Pac J Public Health. 2016; 28(2):134-45. [PubMed: 26733115]

28. Monteiro CA, Conde WL, Popkin BM. Income-specific trends in obesity in Brazil: 1975-2003. Am J Public Health. 2007; 97(10):1808-12. [PubMed: 17761560]

29. Sartorius B, Veerman LJ, Manyema M, Chola L, Hofman K. Determinants of obesity and associated population attributability, South Africa: Empirical evidence from a national panel survey, 2008-2012. PLoS One. 2015; 10(6):e0130218. [PubMed: 26061419]

30. Alaba O, Chola L. Socioeconomic inequalities in adult obesity prevalence in South Africa: a decomposition analysis. Int J Environ Res Public Health. 2014; 11(3):3387-406. [PubMed: 24662998]

31. Kasper NM, Herran OF, Villamor E. Obesity prevalence in Colombian adults is increasing fastest in lower socio-economic status groups and urban residents: results from two nationally representative surveys. Public Health Nutr. 2014; 17(11):2398-406. [PubMed: 24476690] 
32. Aitsi-Selmi A, Chandola T, Friel S, Nouraei R, Shipley MJ, Marmot MG. Interaction between education and household wealth on the risk of obesity in women in Egypt. PLoS One. 2012; 7(6):e39507. [PubMed: 22761807]

33. Monteiro CA, Conde WL, Popkin BM. The burden of disease from undernutrition and overnutrition in countries undergoing rapid nutrition transition: a view from Brazil. Am J Public Health. 2004; 94(3):433-4. [PubMed: 14998807]

34. Iseri A, Arslan N. Obesity in adults in Turkey: age and regional effects. Eur J Public Health. 2008; 19(1):91-4. [PubMed: 19091784]

35. Ergin I, Hassoy H, Kunst A. Socio-economic inequalities in overweight among adults in Turkey: a regional evaluation. Public Health Nutr. 2012; 15(1):58-66. [PubMed: 21859507]

36. Huffman SK, Rizov M. Determinants of obesity in transition economies: the case of Russia. Econ Hum Biol. 2007; 5(3):379-91. [PubMed: 17702676]

37. Chung W, Lee S, Lim S-j, Kim J. Modifying effects of education on the association between lifestyle behaviors and the risk of obesity: evidence from South Korea. BMC Public Health. 2016; 16(1):1100. [PubMed: 27765022]

38. Gordon-Larsen P, Wang H, Popkin BM. Overweight dynamics in Chinese children and adults. Obes Rev. 2014; 15(Suppl 1):37-48. [PubMed: 24341757]

39. Raftopoulou A. Geographic determinants of individual obesity risk in Spain: A multilevel approach. Econ Hum Biol. 2017; 24:185-93. [PubMed: 28088079]

40. Costa-Font J, Hernandez-Quevedo C, Jimenez-Rubio D. Income inequalities in unhealthy life styles in England and Spain. Econ Hum Biol. 2014; 13:66-75. [PubMed: 23639216]

41. Devaux M, Sassi F. Social inequalities in obesity and overweight in 11 OECD countries. Eur J Public Health. 2013; 23(3):464-9. [PubMed: 21646363]

42. Hoffmann K, De Gelder R, Hu Y, et al. Trends in educational inequalities in obesity in 15 European countries between 1990 and 2010. Int J Behav Nutr Phys Act. 2017; 14(1):63. [PubMed: 28482914]

43. Diouf I, Charles MA, Ducimetière P, Basdevant A, Eschwege E, Heude B. Evolution of obesity prevalence in France: an age-period-cohort analysis. Epidemiology. 2010; 21(3):360. [PubMed: 20375843]

44. Rodgers A, Woodward A, Swinburn B, Dietz WH. Prevalence trends tell us what did not precipitate the US obesity epidemic. Lancet Public Health. 2018; 3(4):e162-e3. [PubMed: 29501260]

45. Kwon JW, Song YM, Park H, Sung J, Kim H, Cho SI. Effects of age, time period, and birth cohort on the prevalence of diabetes and obesity in Korean men. Diabetes Care. 2008; 31(2):255-60. [PubMed: 17977938]

46. Wilson R, Abbott JH. Age, period and cohort effects on body mass index in New Zealand, 19972038. Aust N Z J Public Health. 2018; 42(4):396-402. [PubMed: 29972270]

47. Rokholm B, Baker JL, Sorensen TI. The levelling off of the obesity epidemic since the year 1999-a review of evidence and perspectives. Obes Rev. 2010; 11(12):835-46. [PubMed: 20973911]

48. Copley, VR, Bray, C. Changes in children's body mass index in England between 2006/07 and 2015/16: National Child Measurement Programme. London: Public Health England; 2017.

49. Swinburn BA, Sacks G, Hall KD, et al. The global obesity pandemic: shaped by global drivers and local environments. Lancet. 2011; 378(9793):804-14. [PubMed: 21872749]

50. Swinburn B, Egger G, Raza F. Dissecting obesogenic environments: the development and application of a framework for identifying and prioritizing environmental interventions for obesity. Prev Med. 1999; 29(6):563-70. [PubMed: 10600438]

51. Commodore-Mensah Y, Selvin E, Aboagye J, et al. Hypertension, overweight/obesity, and diabetes among immigrants in the United States: an analysis of the 2010-2016 National Health Interview Survey. BMC Public Health. 2018; 18(1):773. [PubMed: 29925352]

52. Locke AE, Kahali B, Berndt SI, et al. Genetic studies of body mass index yield new insights for obesity biology. Nature. 2015; 518(7538):197. [PubMed: 25673413]

53. Boyle EA, Li YI, Pritchard JK. An expanded view of complex traits: from polygenic to omnigenic. Cell. 2017; 169(7):1177-86. [PubMed: 28622505] 
54. Giuliani C, Sazzini M, Bacalini MG, et al. Epigenetic variability across human populations: a focus on DNA methylation profiles of the KRTCAP3, MAD1L1 and BRSK2 genes. Genome Biol Evol. 2016; 8(9):2760-73. [PubMed: 27503294]

55. Gupta VK, Paul S, Dutta C. Geography, ethnicity or subsistence-specific variations in human microbiome composition and diversity. Front Microbiol. 2017; 8:1162. [PubMed: 28690602]

56. Hawks SR, Madanat HN, Merrill RM, Goudy MB, Miyagawa T. A cross-cultural analysis of 'motivation for eating' as a potential factor in the emergence of global obesity: Japan and the United States. Health Promot Int. 2003; 18(2):153-62. [PubMed: 12746387]

57. Rozin, P. Socioiocultural influences on human food selectionWhy we eat what we eat: The psychology of eating. Capaldi, E, editor. Washington, DC: American Psychological Association; 1996. 233-63.

58. Brownell KD, Kersh R, Ludwig DS, et al. Personal responsibility and obesity: a constructive approach to a controversial issue. Health Aff. 2010; 29(3):379-87.

59. Tekes B, Üzümcüoglu Y, Hoe C, Özkan T. The Relationship Between Hofstede's Cultural Dimensions, Schwartz's Cultural Values, and Obesity. Psychol Rep. 2018

60. Egger G, Swinburn B, Islam FA. Economic growth and obesity: an interesting relationship with world-wide implications. Econ Hum Biol. 2012; 10(2):147-53. [PubMed: 22305524]

61. Borovoy A, Roberto CA. Japanese and American public health approaches to preventing population weight gain: A role for paternalism? Soc Sci Med. 2015; 143:62-70. [PubMed: 26344124]

62. World Health Organization. [accessed November 11 2018] Overweight and obesity. 2017. http:// www.who.int/gho/ncd/risk_factors/overweight/en/

63. Development Initiatives. Global Nutrition Report: Nourishing the SDGs. Bristol, UK: Development Initiatives; 2017.

64. Swinburn BK VI, Allender S, et al. The Global Syndemic of Obesity, Undernutrition, and Climate Change: The Lancet Commission Report. Lancet. 2019

65. Gortmaker SL, Swinburn BA, Levy D, et al. Changing the future of obesity: science, policy, and action. Lancet. 2011; 378(9793):838-47. [PubMed: 21872752]

66. Hall KD, Sacks G, Chandramohan D, et al. Quantification of the effect of energy imbalance on bodyweight. Lancet. 2011; 378(9793):826-37. [PubMed: 21872751]

67. Wang YC, McPherson K, Marsh T, Gortmaker SL, Brown M. Health and economic burden of the projected obesity trends in the USA and the UK. Lancet. 2011; 378(9793):815-25. [PubMed: 21872750]

68. Hawkes C, Smith TG, Jewell J, et al. Smart food policies for obesity prevention. Lancet. 2015; 385(9985):2410-21. [PubMed: 25703109]

69. Huang TT, Cawley JH, Ashe M, et al. Mobilisation of public support for policy actions to prevent obesity. Lancet. 2015; 385(9985):2422-31. [PubMed: 25703113]

70. Dietz WH, Baur LA, Hall K, et al. Management of obesity: improvement of health-care training and systems for prevention and care. Lancet. 2015; 385(9986):2521-33. [PubMed: 25703112]

71. Swinburn B, Kraak V, Rutter H, et al. Strengthening of accountability systems to create healthy food environments and reduce global obesity. Lancet. 2015; 385(9986):2534-45. [PubMed: 25703108]

72. Lobstein T, Jackson-Leach R, Moodie ML, et al. Child and adolescent obesity: part of a bigger picture. Lancet. 2015; 385(9986):2510-20. [PubMed: 25703114]

73. Bessesen DH, Van Gaal LF. Progress and challenges in anti-obesity pharmacotherapy. Lancet Diabetes \& Endocrinology. 2018; 6(3):237-48. [PubMed: 28919062]

74. Goodarzi MO. Genetics of obesity: what genetic association studies have taught us about the biology of obesity and its complications. Lancet Diabetes \& Endocrinology. 2018; 6(3):223-36. [PubMed: 28919064]

75. Stefan N, Häring H-U, Schulze MB. Metabolically healthy obesity: the low-hanging fruit in obesity treatment? Lancet Diabetes \& endocrinology. 2018; 6(3):249-58. [PubMed: 28919065]

76. World Health Organization. Global action plan on physical activity 2018-2030: more active people for a healthier world. Geneva: World Health Organization; 2018. 
77. World Health Organization. Report of the Commission on Ending Childhood Obesity. Geneva: World Health Organization; 2016.

78. Olshansky SJ, Ault AB. The fourth stage of the epidemiologic transition: the age of delayed degenerative diseases. The Milbank Quarterly. 1986:355-91. [PubMed: 3762504]

79. Anderson I, Robson B, Connolly M, et al. Indigenous and tribal peoples' health (The LancetLowitja Institute Global Collaboration): a population study. Lancet. 2016; 388(10040):131-57. [PubMed: 27108232]

80. Dyer SM, Gomersall JS, Smithers LG, Davy C, Coleman DT, Street JM. Prevalence and characteristics of overweight and obesity in indigenous Australian children: a systematic review. Crit Rev Food Sci Nutr. 2017; 57(7):1365-76. [PubMed: 26083620]

81. Lucero AA, Lambrick DM, Faulkner JA, et al. Modifiable cardiovascular disease risk factors among indigenous populations. Adv Prev Med. 2014; 2014

82. Katzmarzyk PT. Obesity and physical activity among Aboriginal Canadians. Obesity. 2008; 16(1):184-90. [PubMed: 18223633]

83. Hutchinson RN, Shin S. Systematic review of health disparities for cardiovascular diseases and associated factors among American Indian and Alaska Native populations. PLoS One. 2014; 9(1):e80973. [PubMed: 24454685]

84. Huxley R. Body mass index, waist circumference and waist:hip ratio as predictors of cardiovascular risk-a review of the literature. Eur J Clin Nutr. 2010; 64(1):16-22. [PubMed: 19654593]

85. Singh GM, Danaei G, Farzadfar F, et al. The age-specific quantitative effects of metabolic risk factors on cardiovascular diseases and diabetes: a pooled analysis. PLoS One. 2013; 8(7):e65174. [PubMed: 23935815]

86. Jee SH, Sull JW, Park J, et al. Body-mass index and mortality in Korean men and women. N Engl J Med. 2006; 355(8):779-87. [PubMed: 16926276]

87. Prospective Studies Collaboration. Body-mass index and cause-specific mortality in 900000 adults: collaborative analyses of 57 prospective studies. Lancet. 2009; 373(9669):1083-96. [PubMed: 19299006]

88. Asia Pacific Cohort Studies Collaboration. Body mass index and cardiovascular disease in the Asia-Pacific Region: an overview of 33 cohorts involving 310000 participants. Int J Epidemiol. 2004; 33(4):751-8. [PubMed: 15105409]

89. WHO Consultation. Appropriate body-mass index for Asian populations and its implications for policy and intervention strategies. Lancet. 2004; 363(9403):157-63. [PubMed: 14726171]

90. National Center for Chronic Non Communicable Diseases Control and Prevention. Report on the chronic disease risk factor surveillance in China 2013. Beijing: Military Medical Science Press; 2016.

91. Kandala N-B, Stranges S. Geographic variation of overweight and obesity among women in Nigeria: a case for nutritional transition in Sub-Saharan Africa. PLoS One. 2014; 9(6):e101103. [PubMed: 24979753]

92. Centers for Disease Control and Prevention. [accessed November 28 2017] Adult Obesity Prevalence Maps. Source: Behavioral Risk Factor Surveillance System. 2017. Aug 31, 2016. https://www.cdc.gov/obesity/data/prevalence-maps.html 


\section{Box 1}

\section{Geographic Variation within Countries}

Whilst a national obesity transition model is useful for informing national policies, substantial geographic variation in this transition can exist, thus warranting sub-national obesity prevalence estimates. To explore this further, we conducted an analysis of nationally representative data from India (Supplemental Online Material, p. 4), a country that at the national level is at Stage 1 of the obesity transition. Our new state-level prevalence estimates of obesity (BMI $\geq 30 \mathrm{~kg} / \mathrm{m}^{2}$ ) suggest wide sub-national variation: ranging from $0.6 \%$ in Bihar to $12.2 \%$ in Puducherry among women, and from $0.5 \%$ in Bihar to $7.5 \%$ in Goa among men.

In China, similar to observations in India, there is substantial between-state variation: in 2013, the prevalence of obesity (BMI $\geq 28 \mathrm{~kg} / \mathrm{m}^{2}$ ) ranged from $5.7 \%$ in Hainan and Guangxi to $25.9 \%$ in Beijing. ${ }^{90}$ In Nigeria, the prevalence of overweight and obesity combined (BMI $\geq 25 \mathrm{~kg} / \mathrm{m} 2$ ) in 2008 among women ranged from 10.5\% in Yobe (northeast) to $50.2 \%$ in Lagos. ${ }^{91}$ Sub-national heterogeneity also exists in high-income countries. For example, in the USA, estimates of obesity (BMI $230 \mathrm{~kg} / \mathrm{m}^{2}$ ) based on selfreport data collected in 2016, showed that the prevalence ranged from $22.3 \%$ among adults in Massachusetts to $37.7 \%$ in West Virgina ${ }^{92}$ - a relatively narrower range compared to India, China, and Nigeria. 

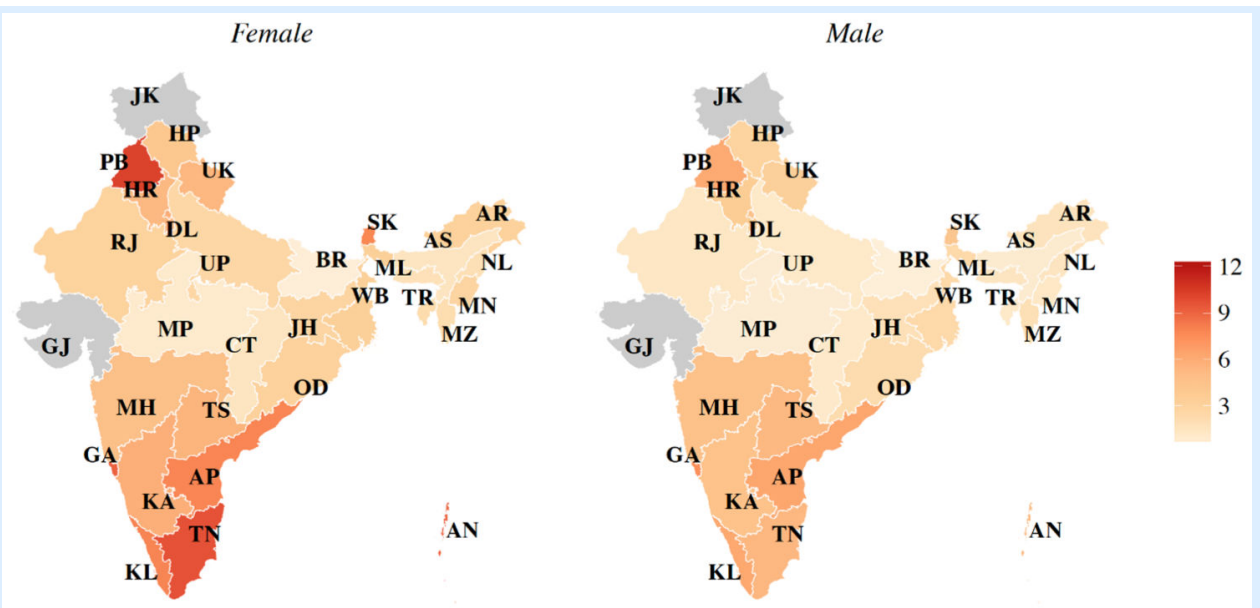

Age-standardized state-level prevalence of obesity (BMI $30 \mathrm{~kg} / \mathrm{m}^{2}$ ) by sex in India. Jammu and Kashmir, and Gujarat are gray to indicate no data were available in the public domain for these states. The Union Territories, Chandigarh, Daman and Diu, and Puducherry are not visible in the map due to their small area. Abbreviations: AP, Andhra Pradesh; AR, Arunachal Pradesh; AS, Assam; BR, Bihar; CT, Chhattisgarh; DL, Delhi; GA, Goa; GJ, Gujarat; HR, Haryana; HP, Himachal Pradesh; JK, Jammu \& Kashmir; JH, Jharkhand; KA, Karnataka; KL, Kerala; MP, Madhya Pradesh; MH, Maharashtra; MN, Manipur; ML, Meghalaya; MZ, Mizoram; NL, Nagaland; OD, Odisha (Orissa); PB, Punjab; RJ, Rajasthan; SK, Sikkim; TN, Tamil Nadu; TS, Telangana State; TR, Tripura; UP, Uttar Pradesh; UK, Uttarakhand (Uttaranchal); WB, West Bengal. 


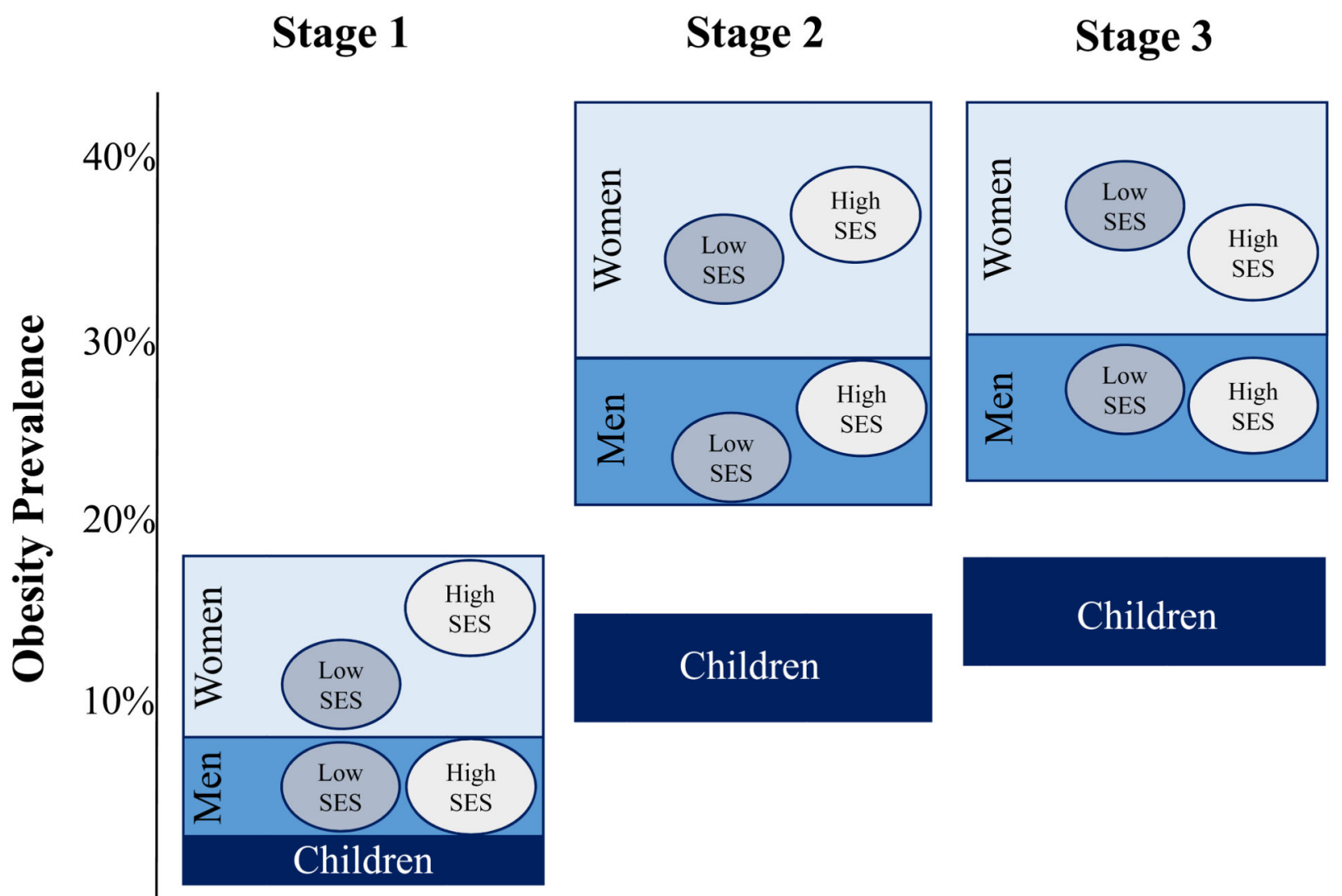

\section{Economic Development with Modification by Local Contextual Factors}

Figure 1.

Conceptual model of the stages of the obesity transition. 

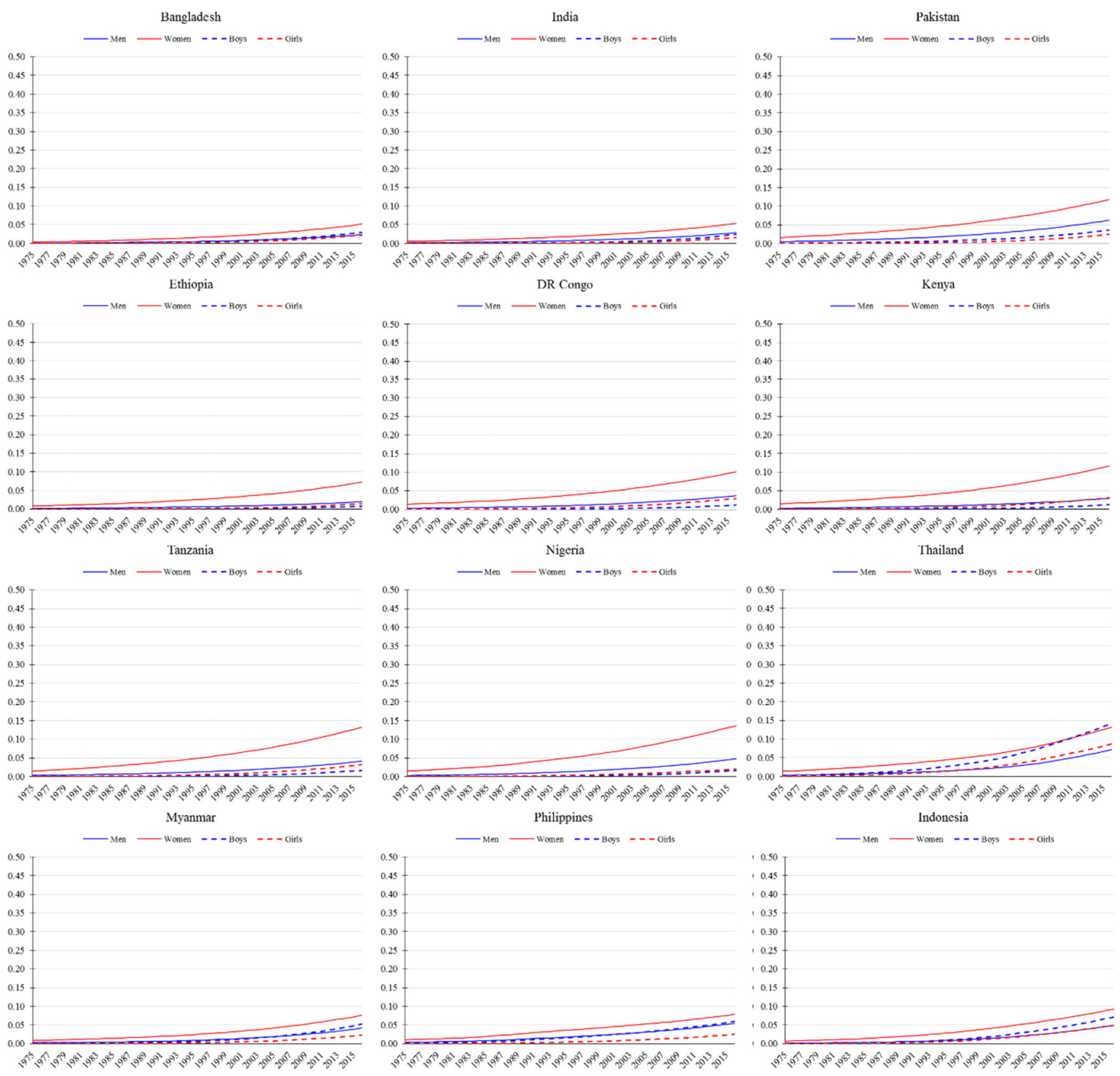

Figure 2.

Trends in age-standardised prevalence of obesity from 1975 to 2016 in mega countries currently at Stage 1 of the obesity transition. Obesity defined as body mass index (BMI) $\geq 30$ $\mathrm{kg} / \mathrm{m}^{2}$ for men and women ( $\geq 20$ years) and BMI $>2$ SD above the median of the WHO growth reference for boys and girls (5-19 years). Data are from the NCD-RisC, 2017. 


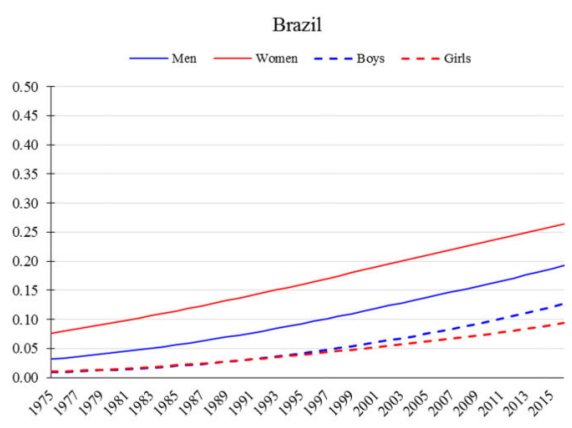

Iran

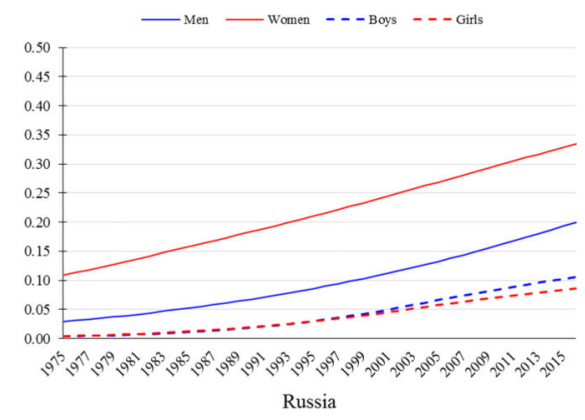

Russia

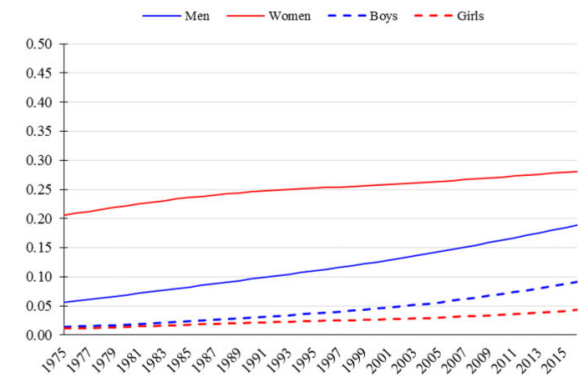

Colombia

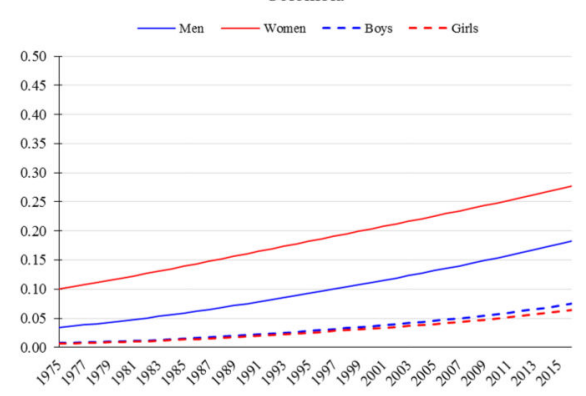

Turkey

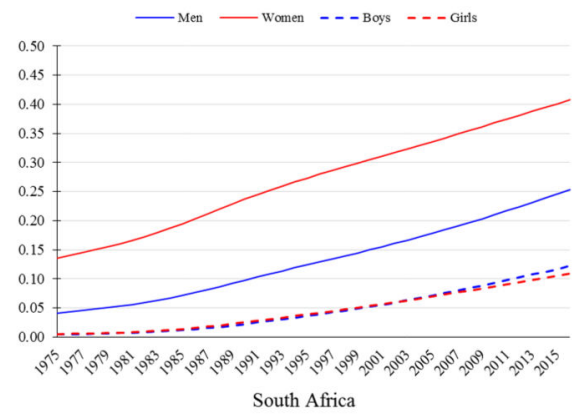

South Africa

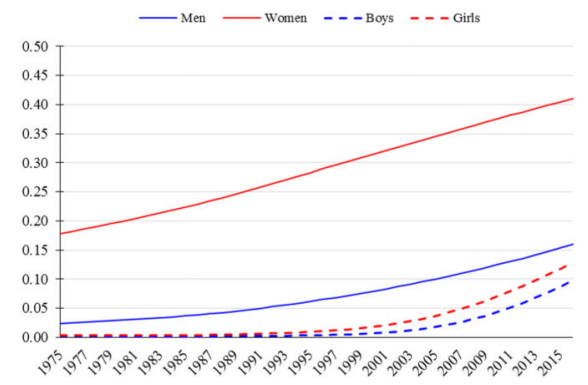

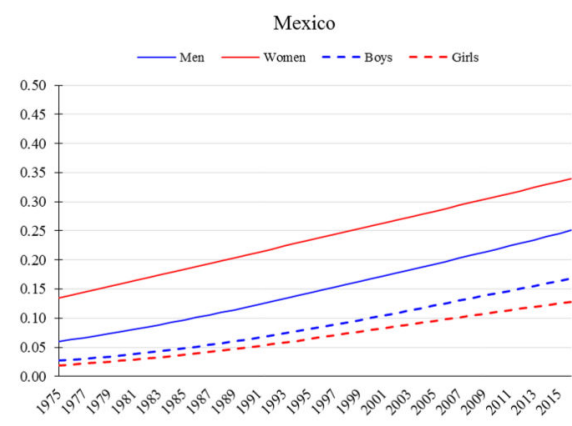

Egypt
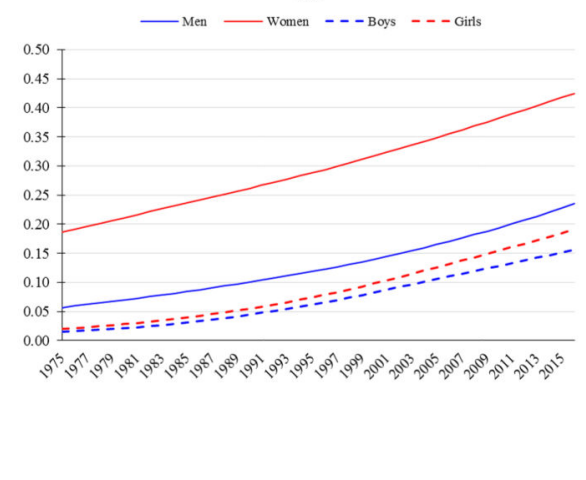

Figure 3.

Trends in age-standardised prevalence of obesity from 1975 to 2016 in mega countries at Stage 2 of the obesity transition. Obesity defined as body mass index (BMI) $230 \mathrm{~kg} / \mathrm{m}^{2}$ for men and women ( $\geq 20$ years) and BMI $>2$ SD above the median of the WHO growth reference for boys and girls (5-19 years). Data are from the NCD-RisC, 2017. 

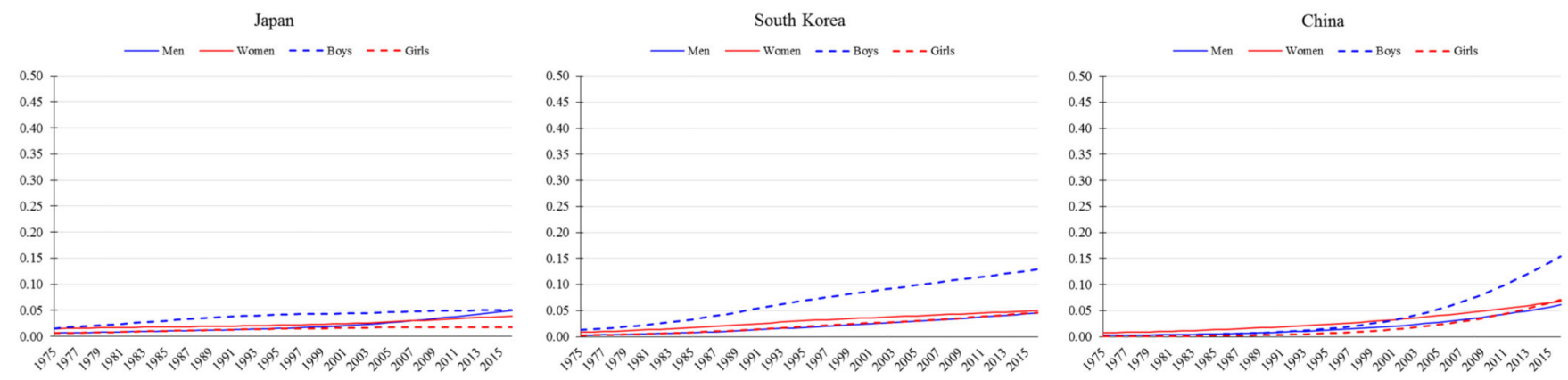

Figure 4.

Trends in age-standardised prevalence of obesity from 1975 to 2016 in East Asian mega countries where cultural moderators of the obesity transition have strongly attenuated the absolute levels of obesity, especially among adults. Obesity defined as body mass index (BMI) $230 \mathrm{~kg} / \mathrm{m}^{2}$ for men and women ( $\geq 20$ years) and BMI $>2$ SD above the median of the WHO growth reference for boys and girls (5-19 years). Data are from the NCD-RisC, 2017. 


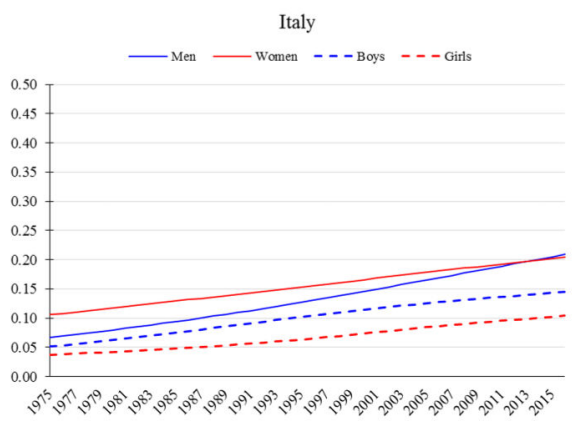

Germany

- Men - Women - - - Boys - - - Girls

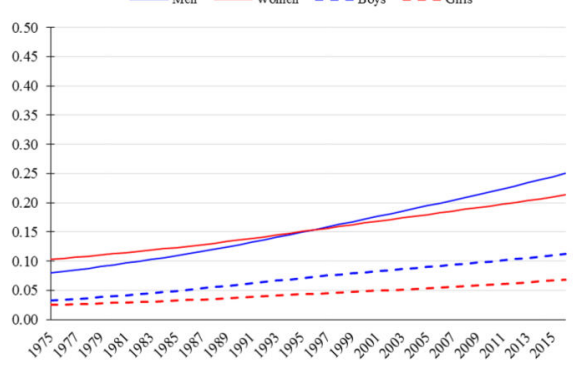

France

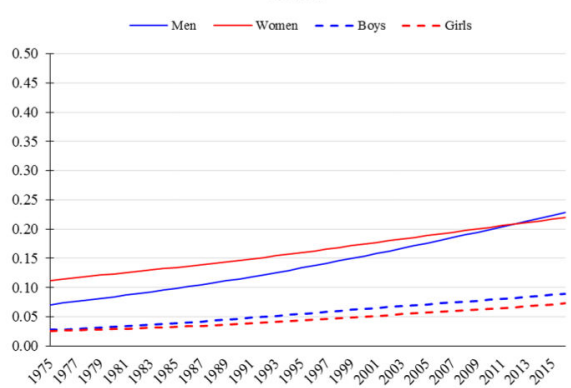

UK

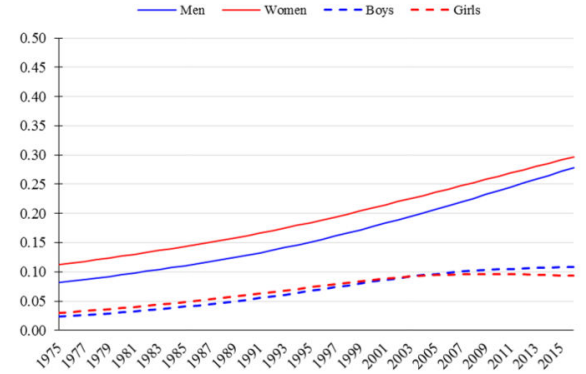

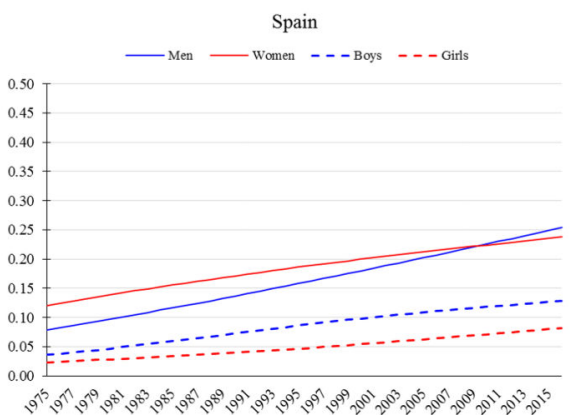

USA

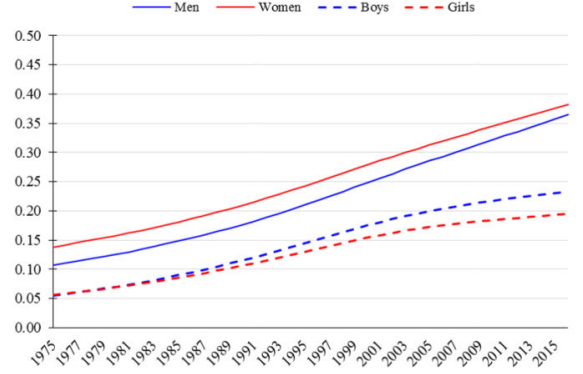

Figure 5.

Trends in age-standardised prevalence of obesity from 1975 to 2016 in mega countries at Stage 3 of the obesity transition. Obesity defined as body mass index (BMI) $30 \mathrm{~kg} / \mathrm{m}^{2}$ for men and women ( $\geq 20$ years) and BMI $>2$ SD above the median of the WHO growth reference for boys and girls (5-19 years). Data are from the NCD-RisC, 2017. 